\title{
Effectiveness of High Flow Nasal Cannula and Standard Non-Rebreathing Mask for Oxygen Therapy in Moderate Category COVID-19 Pneumonia: A Randomized Controlled Study
}

NAZIA Nazir ( $\nabla$ nazunazir@gmail.com )

Government Institute of Medical Sciences https://orcid.org/0000-0001-6950-2111

\section{Anupriya Saxena}

Government Institute of Medical Sciences

Hariom Solanki

Government Institute of Medical Sciences

Ruchi Pandey

Government Institute of Medical Sciences

\section{Research}

Keywords: COVID-19, Hypoxemia, Intensive Care Unit, Non-Invasive Ventilation, Oxygen Therapy, Pneumonia, Respiratory failure.

Posted Date: June 28th, 2021

DOI: https://doi.org/10.21203/rs.3.rs-659154/v1

License: (1) This work is licensed under a Creative Commons Attribution 4.0 International License.

Read Full License 


\section{Abstract}

Background: To compare the effectiveness of High Flow Nasal Cannula (HFNC) and standard non rebreathing mask (NRBM) as oxygen delivery device, in moderate cases of COVID-19 Pneumonia.

Methods: A single-centre, prospective, open label randomized controlled trial was conducted between February 2021 and April 2021. Sixty enrolled patients were randomly divided into two groups according to the oxygen delivery device used. Group $1(n=30)$ received HFNC and group $2(n=30)$ received NRBM as initial oxygen delivery device, to maintain a target saturation of $\geq 96 \%$ in both groups. The success rate of oxygen therapy, time to progression to severe disease, $\mathrm{PaO}_{2}, \mathrm{PaO}_{2} / \mathrm{FiO}_{2}$ ratio, respiratory rate, heart rate, blood pressure, number of patients requiring NIV or endotracheal intubation, time for de-escalation of oxygen therapy to lower Fio2 device and patient satisfaction level were compared among the two groups.

Results: Demographic, clinical variables and treatment given were comparable in the two groups. In the HFNC group 83.3\% patients had successful outcomes with the initial oxygen therapy device used as compared to $66.6 \%$ in the NRBM group. However, the use of HFNC resulted in improved oxygenation $(\mathrm{P}<$ $0.001)$, better patient satisfaction $(P<0.001)$ and shorter time for de-escalation of oxygen therapy to a lower $\mathrm{FIO}_{2}$ device $(3.75 \pm 1.032$ vs. $6.83 \pm 0.928)$.

Conclusions: HFNC is a reliable oxygen therapy modality for moderate category COVID-19 pneumonia that results in better oxygenation and a greater patient satisfaction level as compared to a nonrebreathing mask.

Trial Registration: ctri.nic.in;

Reg No: CTRI/2021/01/030829;

Date of Reg: 05/02/2021

\section{Background}

The COVID-19 pandemic caused by a newly discovered SARS-CoV-2 virus is a primarily respiratory illness that causes acute hypoxemia. Due to its great contagiousness, it spread around the entire globe and led to a public health emergency of international concern [1]. Most COVID 19 positive patients have mild respiratory symptoms. However, $14 \%$ of patients have hypoxic respiratory failure requiring hospitalisation with supplemental oxygen administration [2]. The incidence of severe acute respiratory failure despite conventional oxygen therapy is reported to be 5\% in COVID 19 pneumonia [3].

Optimal oxygenation is the cornerstone of the management of moderate \& severe COVID pneumonia patients [4]. However, it is unknown which type of support is the most effective, limiting the ability to improve clinical outcomes and appropriately allocate resources. 
The updated clinical management guidelines of COVID 19, (dated 03.05.2020 version 5) given by Government of India, Ministry Of Health And Family Welfare (MOHFW) divided the patients of SARS-CoV-

2 into categories of mild, moderate \& severe, based on clinical severity. ${ }^{[5]}$ For the moderate category patients, clinical management includes oxygen therapy to maintain target 02 saturation $\geq 92-96 \%$ [5]. However, there is no guideline to justify the advantage of one form of oxygen $\left(\mathrm{O}_{2}\right)$ therapy device over the other. Various oxygen devices ranging from simple masks to High Flow Nasal Cannula (HFNC) can be used for these patients [5]. In order to guide clinical practice, it is imperative to understand the comparative effectiveness of the two oxygen therapy devices used most commonly worldwide in moderate cases of COVID 19 Pneumonia: standard non rebreathing mask (NRBM) or High Flow Nasal Cannula (HFNC). Hence, this study was planned based on the hypothesis that early institution of HFNC in moderate category COVID 19 pneumonia patients results in improved outcome in terms of reduced number of patients progressing to severe disease and better oxygenation as compared to NRBM.

We hereby report the results of a randomized trial conducted to determine whether early treatment with HFNC, as compared to NRBM, can prevent the development of increased hypoxemia in COVID 19 positive patients.

\section{Methods}

This study was a single-centre, open-label, randomised controlled study conducted in a COVID hospital from February 2021 to April 2021. This clinical study was performed following Ethical Principles for Medical Research involving Human Subjects, outlined in the Helsinki Declaration of 1975 (revised 2013). The protocol was approved by the institutional ethics committee and was registered on ctri.nic.in (CTRI/2021/01/030829). Written informed consent was obtained from all enrolled subjects according to committee recommendations.

Operational definition of moderate category COVID 19 pneumonia: Pneumonia with no signs of severe disease with clinical features consisting of dyspnoea (respiratory rate $24-30 / \mathrm{min}$ ), hypoxia $\left(\mathrm{SpO}_{2}: \leq\right.$ 94\% [range 90-94\%] on room air), fever and cough. Operational definition of severe category COVID 19 pneumonia [5]: Pneumonia with signs of severe disease with clinical features consisting of respiratory distress (respiratory rate $>30 / \mathrm{min}$ ), hypoxia $\left(\mathrm{SpO}_{2}:<90 \%\right.$ on room air), fever and cough.

Keeping the success of oxygen therapy as the primary outcome, a pilot study was conducted with five moderate category COVID 19 patients in each group. Using open epi software version 3, presuming successful outcome in $60 \%$ patients in group 1 and $20 \%$ patients in group 2 to be true, with confidence of $95 \%$, power $80 \%$, allocation ratio 1: 1, the sample size calculated was a total of 48 patients with 24 patients in each group. A total of 30 patients were taken in each group to compensate for drop outs.

All COVID positive patients of moderate category, of age $\geq 16$ years who were eligible and gave informed consent for study inclusion were randomly allocated into two study groups according to the oxygenation device used. Randomisation was done by computer generated randomisation list. In group 1, patients 
received oxygen therapy with HFNC set at a flow rate of 40-60 L/min, fractional inspiratory oxygen concentration $\left(\mathrm{FiO}_{2}\right)$ 0.8-1 adjusted to maintain oxygen saturation $\left(\mathrm{SpO}_{2}\right) \geq 96-99 \%$. The control of $\mathrm{FiO}_{2}$ was achieved by using an air oxygen blender (Draeger ${ }^{\circledR}$, Oxymixture MP04200). In group 2, patients received oxygen therapy with NRBM used at a flow rate of $12-15 \mathrm{~L} / \mathrm{min}, \mathrm{FiO}_{2} 0.8-1$, adjusted to maintain $\mathrm{SpO}_{2} \geq 96-99 \%$. With NRBM, the $\mathrm{FiO}_{2}$ was measured using a portable oxygen analyser. (MX 300, Teledyne ${ }^{\circledR}$ Analytical Instruments) Patients of severe category of COVID pneumonia, Glasgow Coma scale $\leq 12$ and those with primary pulmonary disease, tracheostomy or any nasal/facial defect that could impede HFNC or NRBM use were excluded from the study.

Primary outcomes noted were success of oxygen therapy which was defined as not requiring replacement to a higher oxygen delivery device and the time to progression to severe disease. Secondary outcomes noted were, success of oxygen therapy which was defined as not requiring replacement to a higher oxygen delivery device partial pressure of arterial oxygen $\left(\mathrm{PaO}_{2}\right)$, ratio of partial pressure of oxygen to fraction of inspiratory oxygen concentration $\left(\mathrm{PaO}_{2} / \mathrm{FiO}_{2}\right)$, respiratory rate (RR), heart rate (HR), mean arterial pressure (MAP), number of patients requiring NIV, number of patients requiring endotracheal intubation, time for de-escalation of oxygen therapy to lower $\mathrm{FiO}_{2}$ device and patient satisfaction level. The patient satisfaction level was measured using a visual analogue scale (VAS) [6]. A satisfaction VAS is a $100-\mathrm{mm}$ long horizontal line. There are two adjectives at the beginning and finish that symbolise extremes of satisfaction (i.e., no satisfaction and extreme satisfaction). The patient marked a vertical mark on the 100-mm line to indicate his level of pleasure. The millimetre measurement was translated to the same number of decimal points, ranging from 0 to 10. "Are you comfortable with the oxygen therapy device you're using?" was the actual inquiry. Under the VAS horizontal line, there was a standard instruction on how to fill out the VAS form.

Device failure was considered if the patient progressed to severe category COVID 19 pneumonia while on the study device and required escalation of oxygen therapy [5]. In case of device failure, the decision for shifting to higher oxygen delivery device (including HFNC for the patients in NRBM group or NIV or endotracheal intubation) was done according to the attending anaesthesiologist decision taking respiratory rate, work of breathing and oxygen saturation into account. The patients were followed up daily for monitoring disease progression by various vital parameters up to 14 days.

Vital parameters including $\mathrm{HR}, \mathrm{MAP}, \mathrm{RR}, \mathrm{PaO}_{2}, \mathrm{PaO}_{2} / \mathrm{FiO}_{2}, \mathrm{SpO}_{2}$ and arterial blood gas (ABG) analysis were done as per Intensive Care Unit (ICU) protocol. In both groups, $\mathrm{SpO}_{2}$ was monitored continuously and $\mathrm{FiO}_{2}$ was titrated on an hourly basis to maintain $\mathrm{SpO}_{2}$ between $\geq 96 \%$. The assigned treatment was administered continuously and patients were assessed for treatment success. Patients were weaned to a lower $\mathrm{FiO}_{2}$ oxygen therapy device when the following criteria were met: respiratory rate $\leq 24 \mathrm{breaths} / \mathrm{min}$; no recruitment of accessory muscles during calm breathing; haemodynamic stability (HR $<120$ /min; MAP between 70 and $110 \mathrm{mmHg}$ with no hemodynamically significant arrhythmias), $\mathrm{PaO}_{2}>80$ and $\mathrm{SpO}_{2} \geq$ $96 \%$. Patients from both groups underwent a standard treatment for COVID 19 with physiotherapy and awake proning protocol. 
Statistical analysis was performed with Statistical Package for the Social Sciences (SPSS) software for Windows (Ver. 24.0, IBM Corp., USA). Categorical variables are reported as count and frequency/ per cent while continuous variables are reported as mean and standard deviation or median and interquartile range as appropriate. Associations were tested using student $t$ test for parametrically distributed continuous variables and by using Mann Whitney $\mathrm{U}$ test for non-parametrically distributed variables. For categorical variables associations were tested using either Chi square test or Fisher's exact test where appropriate. The alpha level was set at 0.05 for statistical significance.

\section{Results}

Between February 2021 and April 2021, 60 patients who consented to participate in this study were randomly divided into two groups (Fig. 1). 30 patients were included in group1 (HFNC group) and 30 patients in group 2 (NRBM group). Demographics, most relevant clinical characteristics, main comorbidities, $A B G$ on admission and treatment received were comparable in the two study groups (Table 1).

Table 1

Baseline Patient Characteristics

\begin{tabular}{|c|c|c|c|}
\hline Parameters & HFNC $^{*}$ & NRBM $^{*}$ & P value $^{\dagger}$ \\
\hline Gender (Male) $)^{\ddagger}$ & $14(n=30)$ & $16(n=30)$ & \\
\hline AGE & $54.00 \pm 11.447$ & $59.63 \pm 3.034$ & 0.012 \\
\hline HEART RATE & $88.03 \pm 1.829$ & $86.23 \pm 2.582$ & 0.029 \\
\hline MAP§ & $73.50 \pm 2.146$ & $73.23 \pm 1.870$ & 0.6 \\
\hline $\mathrm{PaO}_{2} \|$ & $65.07 \pm 1.701$ & $65.73 \pm 1.999$ & 0.1736 \\
\hline $\mathrm{PaO}_{2} / \mathrm{FiO}_{2}$ & $207.03 \pm 4.56$ & $207.67 \pm 3.790$ & 0.556 \\
\hline $\mathrm{SpO}_{2}$ ** & $91 \pm 1.541$ & $92 \pm 1.022$ & 0.044 \\
\hline Respiratory Rate & $28.20 \pm 1.157$ & $28.10 \pm 1.242$ & 0.748 \\
\hline \multicolumn{4}{|c|}{$\begin{array}{l}{ }^{*} \text { Values are presented as mean } \pm \mathrm{SD} \text {. }{ }^{\dagger} \mathrm{P} \text { value less than } 0.05 \text { is considered significant. }{ }^{\ddagger} \text { Values } \\
\text { expressed as numbers, } \$ \mathrm{MAP}: \text { mean arterial blood pressure, } " \mathrm{PaO}_{2}: \text { Partial Pressure of Oxygen, } \\
\mathrm{PaO}_{2} / \mathrm{FiO}_{2} \text { : ratio of Partial Pressure of Oxygen and Fraction of inspiratory oxygen concentration } \\
\star \star \mathrm{SpO}_{2}: \text { Saturation of oxygen, }{ }^{\star \star}, \mathrm{\dagger} \text {, 㧊 }\end{array}$} \\
\hline
\end{tabular}

Among the 60 patients, 45 were successfully treated with the initial oxygen therapy device they received. In group 1, 25 out of 30 patients (83.3\%) had successful outcomes on HFNC and in group 2, 20 out of 30 $(66.6 \%)$ were successfully managed on NRBM. Although the success rate of oxygen therapy by HFNC 
was higher than that by the non-rebreathing mask, the difference was not statistically significant (Table 2) $(P=0.136)$. The median time to progression to severe disease was 6 and 5.5 days in group 1 and 2 respectively, with no statistically significant difference among the two groups (Table 2$)(P=0.859)$.

Table 2

Primary and Secondary Outcomes

\begin{tabular}{|c|c|c|c|}
\hline PARAMETERS & $\begin{array}{l}\text { HFNC } \\
(n=30)^{*}\end{array}$ & $\begin{array}{l}\text { NRBM } \\
(n=30)^{*}\end{array}$ & $P_{\text {value }}^{\dagger}$ \\
\hline Success of oxygen therapy & $25(83.3)$ & $20(66.6)$ & 0.136 \\
\hline Patients requiring escalation of oxygen therapy & $5(16.6)$ & $10(33.3)$ & 0.136 \\
\hline Time to progression to severe disease $\mathrm{e}^{\ddagger}$ & $6(4.5-6.5)^{\ddagger}$ & $5.5(5-6)$ & 0.859 \\
\hline Patients requiring intubation & $1(3.3)$ & $3(10)$ & 0.612 \\
\hline
\end{tabular}

In group 1, five patients failed to respond to the initial treatment with the HFNC and progressed to the severe category and received NIV. One patient among these five was later intubated and mechanically ventilated. In group 2, a total of ten patients required escalation of oxygen therapy device. Among these ten patients, five were shifted to HFNC, out of which three were successfully managed. Remaining seven patients received NIV and three were later intubated and mechanically ventilated.

Use of $\mathrm{HFNC}$ in group 1 , significantly improved the $\mathrm{PaO}_{2}$ and $\mathrm{PaO}_{2} / \mathrm{FiO}_{2}$ ratio during the course of treatment as compared to the non-rebreathing mask ( $84.23 \pm 9.202$ vs. $74.27 \pm 4.160$ and $264.60 \pm 42.019$ vs. $216.62 \pm 23.868$, respectively). Respiratory rate in group $1(23.17 \pm 2.086)$ was significantly lower than in group $2(25.52 \pm 0.871)(P=0.0018)$. Time for de-escalation of oxygen therapy to a lower $\mathrm{FiO}_{2}$ device was also significantly shorter in the group $1(3.75 \pm 1.032$ vs. $6.83 \pm 0.928)(P<0.001)($ Table 3$)$. 
Table 3

Time and Vital Parameters on the Study Device

\begin{tabular}{|c|c|c|c|c|}
\hline Parameters & $\mathrm{HFNC}^{*}$ & NRBM* & $\begin{array}{l}P \\
\text { value }^{\dagger}\end{array}$ & $\begin{array}{l}95 \% \text { of } \mathrm{Cl} \text { of } \\
\text { difference }\end{array}$ \\
\hline $\begin{array}{l}\text { Average time for de-escalation of } \\
\text { oxygen therapy }\end{array}$ & $3.75 \pm 1.032$ & $6.83 \pm 0.928$ & $<.001$ & $\begin{array}{l}-3.078(-3.619- \\
[-2.537])\end{array}$ \\
\hline $\mathrm{PaO}_{2}$ on device $\S$ & $\begin{array}{l}84.23 \pm \\
9.202\end{array}$ & $\begin{array}{l}74.27 \pm \\
4.160\end{array}$ & 0.0001 & $\begin{array}{l}9.967(6.276- \\
13.657)\end{array}$ \\
\hline $\mathrm{PaO}_{2} / \mathrm{FiO}_{2}$ on device ${ }^{\|}$ & $\begin{array}{l}264.60 \pm \\
42.019\end{array}$ & $\begin{array}{l}216.62 \pm \\
23.868\end{array}$ & 0.0001 & $\begin{array}{l}47.979(30.080- \\
65.878)\end{array}$ \\
\hline $\mathrm{SpO}_{2}$ on device & $\begin{array}{l}95.17 \pm \\
4.662\end{array}$ & $\begin{array}{l}93.53 \pm \\
4.911\end{array}$ & 0.7719 & $\begin{array}{l}1.633(-0.841- \\
4.108)\end{array}$ \\
\hline Respiratory Rate & $\begin{array}{l}23.17 \pm \\
2.086\end{array}$ & $\begin{array}{l}25.52 \pm \\
0.871\end{array}$ & 0.0018 & $\begin{array}{l}-1.351(-2.189- \\
[-0.512])\end{array}$ \\
\hline Heart Rate & $\begin{array}{l}86.83 \pm \\
3.815\end{array}$ & $\begin{array}{l}87.03 \pm \\
1.732\end{array}$ & 0.794 & $\begin{array}{l}-0.20(-1.0731- \\
1.331)\end{array}$ \\
\hline MAP ${ }^{\star \star}$ & $\begin{array}{l}74.00 \pm \\
1.661\end{array}$ & $\begin{array}{l}73.20 \pm \\
1.648\end{array}$ & 0.661 & $\begin{array}{l}0.80(-0.055- \\
1.655)\end{array}$ \\
\hline Patient Satisfaction Level & $6.07 \pm 0.691$ & $2.80 \pm 0.761$ & 0.001 & \\
\hline \multicolumn{5}{|c|}{ 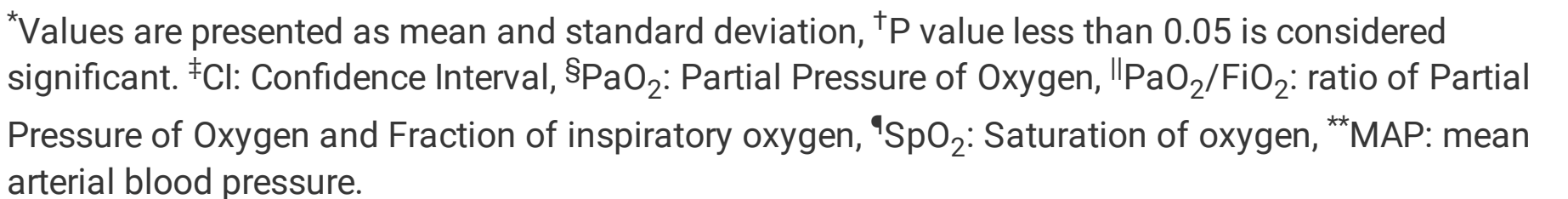 } \\
\hline
\end{tabular}

No significant difference in HR and MAP was observed among the groups. Patient satisfaction level as measured by VAS Scale was higher in the HFNC group than in the NRBM group $(P<0.001)$ (Fig. 2$)$.

\section{Discussion}

The primary strategy for COVID-19 pneumonia patients is supportive care, including oxygen therapy for hypoxemic patients [7], in which High-Flow Nasal Cannula (HFNC) has been reported to be effective in improving oxygenation [8]. The choice of oxygen support devices for oxygen therapy is essential in these patients in terms of effectiveness, patient comfort and generation of aerosol.

The primary outcome noted in our study were success of oxygen therapy compared between the two groups and the time of progression to severe disease. Although the success rate of oxygen therapy by HFNC was higher than that by the non-rebreathing mask (NRBM), the difference was not statistically significant $(P=0.136)$. Also, the difference in median time of progression to severe disease among the two groups was statistically insignificant $(P=0.859)$. 
On analysis of secondary outcomes, we noted that the use of the HFNC resulted in improved oxygenation and a decreased work of breathing. The high flow rates (up to $60 \mathrm{~L} / \mathrm{min}$ ) delivered by HFNC that match patients' peak inspiratory flow, meet the higher oxygen requirements of dyspnoeic hypoxemic COVID patients and could have resulted in better patient outcomes. In addition, a fixed $\mathrm{FiO}_{2}$ with a small degree of positive pressure in the airways that increases end-expiratory volume and decreases the nasopharyngeal dead space enhances carbon dioxide removal by preventing rebreathing $[9,10]$.

Patients in group 1 also reported better satisfaction with a shorter time of de-escalation to lower oxygen requirement as compared to group 2. Delivery of heated and humidified oxygen from $21-100 \%$ by HFNC makes it more comfortable for the airways resulting in increased tolerance and better patient satisfaction $[11,12,13]$. The results of our study stand in agreement with our prior hypothesis.

A similar study by Song et al. [14], (before the COVID pandemic) concluded that at a fixed inspired oxygen fraction, the application of a HFNC after extubation achieves a higher success rate of oxygen therapy and less discomfort at $24 \mathrm{~h}$ than an air entrainment mask in patients with acute respiratory failure. A Systematic review on the effectiveness of HFNC and conventional oxygen therapy (COT) concluded that the use HFNC may reduce the need for invasive ventilation and escalation of therapy compared with COT in COVID-19 patients with acute hypoxemic respiratory failure (although the review did not include any eligible study in COVID19 patients) [15].

The concern for aerosol dispersion has been a major limiting factor in the use of HFNC in COVID 19 patients $[16,17]$. Adequate personal protective equipment, adequate room ventilation and use of highfiltration fit-tested respirators for all healthcare workers attending to patients were available. In addition, use of a surgical face mask on patients receiving HFNC was mandatory as per our hospital protocol. Now the evidence also suggests that the risk of airborne transmission is no greater than the use of a face mask $[18,19]$. On-going field experiments and clinical studies during the current COVID pandemic may provide additional information.

This study emphasizes the importance of timely management of moderate category hypoxaemic COVID19 patients. Early institution of HFNC may help reduce the mortality and morbidity associated with this condition. In addition, the use of HFNC outside the ICU could be a rational practice in such patients resulting in substantial reduction in demand for ventilators. This could increase the capacity to manage COVID-19 pneumonia patients in a resource limited setting where the infrastructure and or expertise of ICU care is limited [20].

To our knowledge and a thorough literature search, we did not come across a similar study done on COVID-19 pneumonia patients. There are some studies comparing effectiveness of HFNC Vs. conventional oxygen therapies before the emergence of COVID 19 [21, 22, 23, 24, 25, 26]. However, no randomised controlled trial that has included COVID-19 patients for such comparison could be found.

The limitations of our study were that firstly, it is an open label study so the possibility of information bias can't be excluded although most of our variables were objective in nature. Another limitation was 
that the study only reflected the experience from a single centre with a small sample size which may have overestimated the effect of treatment. This could limit generalisation of the results.

\section{Conclusion}

HFNC as an oxygen therapy modality for moderate category COVID-19 pneumonia is a feasible option which can result in better oxygenation and a greater patient satisfaction level than a non-rebreathing mask. Early institution of HFNC during the moderate phase of disease may shorten the time to deescalation of oxygen device, and thus avoiding non-invasive ventilation and intubation. This can reduce the burden of critical care in the testing time of pandemic.

\section{Abbreviations}

HFNC: High Flow Nasal Cannula

NRBM: Non rebreathing mask

SARS COV-2: severe Acute respiratory Syndrome Coronavirus 2

COVID 19: Coronavirus Disease

MOHFW: Ministry of health and Family Welfare

02: Oxygen

SPO2: Oxygen Saturation

FiO2: fraction of inspiratory oxygen concentration

RR: Respiratory rate

PaO2: Partial Pressure of Oxygen

HR: Heart Rate

MAP: Mean arterial pressure

NIV: Non-invasive ventilation

VAS: Visual Analog Score

ABG: Arterial Blood Gas

ICU: Intensive Care Unit

SPSS: Statistical Package for the Social Sciences 


\section{Declarations}

Ethics approval and consent to participate: The study was approved by the Institutional Ethics Committee of Government Institute Of Medical Sciences. IEC Reference number: GIMS/IEC/HR/2020/50

Consent for publication: Not Applicable

Availability of data and materials: The datasets used and analysed are available with the corresponding author.

Competing interests: The authors declare that they have no competing interests

Funding: None

Authors' contributions: NN and AS contributed in Concept, design, definition of intellectual content, literature search, data acquisition, manuscript preparation, manuscript editing and manuscript review. HS and RP contributed towards data acquisition, data analysis and statistical analysis and manuscript editing. All the authors take responsibility for the integrity of the work as a whole from inception to published article and NN is designated as 'corresponding author'. All authors read and approved the final manuscript

Acknowledgements: Not applicable

\section{References}

1. Infection prevention and control when novel coronavirus infection is suspected. Interim Guidance. WHO. Available fromhttps://www.who.int/publications-detail/infection-prevention-and-controlduringhealth-care-when-novel-coronavirus-(ncov)-infection-issuspected-20200125.

2. Wu Z, McGoogan JM. Characteristics of and important lessons from the coronavirus disease 2019 (COVID-19) outbreak in China: summary of a report of 72314 cases from the Chinese Center for Disease Control and Prevention. JAMA2020;323:1239-42.

3. Mehta Y, Chaudhry D, Abraham OC, Chacko J, Divatia J, Jagiasi B, et al. Critical Care for COVID-19 Affected Patients: Position Statement of the Indian Society of Critical Care Medicine. Indian J Crit Care Med 2020; 24: 222-41.

4. Gibson PG, Qin L, Puah SH. COVID-19 acute respiratory distress syndrome (ARDS): clinical features and differences from typical pre-COVID-19 ARDS. Med J Aust 2020;213:54-6.

5. Clinical Management Protocol: COVID-19 Government of India Ministry of Health and Family Welfare Directorate General of Health Services (EMR Division) Version 5 03.07.20. Available from www.mohfw.gov.in 
6. Mc Cormack HM, Horne DJ, Sheather S. Clinical applications of visual analogue scales: a critical review. Psychol Med 1988; 18:1007-19.

7. World Health Organisation. Clinical Management of Severe Acute Respiratory Infection (SARI) when COVID-19 Disease is Suspected - Interim Guidance. WHO, 13 March 2020

8. Guy T, Créac'hcadec A, Ricordel C, Salé A, Arnouat B, Bizecet J L, et al. High-flow nasal oxygen: a safe, efficient treatment for COVID-19 patients not in an ICU. Eur Respir J 2020; 56: 2001154.

9. Nishimura M. High-Flow Nasal Cannula Oxygen Therapy in Adults: Physiological Benefits, Indication, Clinical Benefits, and Adverse Effects. Respir Care 2016; 61: 529-41

10. Lodeserto FJ, Lettich TM, Rezaie SR. High-flow Nasal Cannula: Mechanisms of Action and Adult and Pediatric Indications. Cureus 2018; 10:e3639.

11. Maggiore SM, Idone FA, Vaschetto R, Festa R, Cataldo A, Antonicelli F, et al. Nasal high-flow versus Venturi mask oxygen therapy after extubation. Effects on oxygenation, comfort, and clinical outcome. Am J Respir Crit Care Med 2014; 190: 282-8.

12. Lalla U, Allwood BW, Louw EH, Nortje A, Parker A, Taljaard JJ, et al. The utility of high-flow nasal cannula oxygen therapy in the management of respiratory failure secondary to COVID-19 pneumonia. S Afr Med J 2020;110:432.

13. Vourc'h M, Baud G, Feuillet F, Blanchard C, Mirallie E, Guitton C, et al. High-flow Nasal Cannulae Versus Non-invasive Ventilation for Preoxygenation of Obese Patients: The PREOPTIPOP Randomized Trial. E Clin Medi 2019;13: 112-9.

14. Song HZ, Gu JX, Xiu HQ, Cui W, Zhang GS. The value of high-flow nasal cannula oxygen therapy after extubation in patients with acute respiratory failure. Clinics (Sao Paulo) 2017; 72:562-7.

15. Agarwal A, Basmaji J, Muttalib F,Granton D , Chaudhuri D, Chetan D et al. High-flow nasal cannula for acute hypoxemic respiratory failure in patients with COVID-19: systematic reviews of effectiveness and its risks of aerosolization, dispersion, and infection transmission. Can J Anaesth 2020; 67: 1217-48.

16. World Health Organization (2020) Report of the WHO-China joint mission on coronavirus disease 2019 (COVID-19). https://www.who.int/publications/i/item/report-of-the-who-china-joint-mission-oncoronavirus-disease-2019-(covid-19).

17. Liu Y, Ning Z, Chen Y, Guo M, Liu Y, Gali NK, et al. Aerodynamic analysis of SARS-CoV-2 in two Wuhan hospitals. Nature 2020; 582:557-60.

18. Li J, Fink JB, Ehrmann S. High-flow nasal cannula for COVID-19 patients: low risk of bio-aerosol dispersion. Eur Respir J 2020; 14:2000892.

19. Haymet A, Bassi G.L, Fraser J.F. Airborne spread of SARS-CoV-2 while using high-flow nasal cannula oxygen therapy: myth or reality? Intensive Care Med 2020; 46: 2248-51.

20. Calligaroa GL, Lallac U, Audleyd G, Ginaa P, Millerb MG, Mendelsone M, et al. The utility of high-flow nasal oxygen for severe COVID-19 pneumonia in a resource-constrained setting: A multi-centre prospective observational study. EClin Med 2020;28: 100570. 
21. Ni YN, Luo J, Yu H, Liu D, Ni Z, Cheng J, et al. Can High-flow Nasal Cannula Reduce the Rate of Endotracheal Intubation in Adult Patients With Acute Respiratory Failure Compared With Conventional Oxygen Therapy and Noninvasive Positive Pressure Ventilation?: A Systematic Review and Meta-analysis. Chest 2017; 151:764-75.

22. Huang HW, Sun XM, Shi ZH, Chen GQ, Chen L, Friedrich JO, et al. Effect of High-Flow Nasal Cannula Oxygen Therapy Versus Conventional Oxygen Therapy and Noninvasive Ventilation on Reintubation Rate in Adult Patients After Extubation: A Systematic Review and Meta-Analysis of Randomized Controlled Trials. J Intensive Care Med 2018; 33:609-23.

23. Lee CC, Mankodi D, Shaharyar S, Ravindranathan S, Danckers M, Herscovici P, et al. High flow nasal cannula versus conventional oxygen therapy and non-invasive ventilation in adults with acute hypoxemic respiratory failure: A systematic review. Respir Med 2016; 121:100-8.

24. Maitra S, Som A, Bhattacharjee S, Arora MK, Baidya DK. Comparison of high-flow nasal oxygen therapy with conventional oxygen therapy and noninvasive ventilation in adult patients with acute hypoxemic respiratory failure: A meta-analysis and systematic review. J Crit Care 2016; 35:138-44.

25. Zhao H, Wang H, Sun F, Lyu S, Youzhong A. High-flow nasal cannula oxygen therapy is superior to conventional oxygen therapy but not to noninvasive mechanical ventilation on intubation rate: a systematic review and meta-analysis. Crit Care 2017; 12:184.

26. Rochwerg B, Granton D, Wang DX, Helviz Y, Einav S, Frat JP, et al. High flow nasal cannula compared with conventional oxygen therapy for acute hypoxemic respiratory failure: a systematic review and meta-analysis. Intensive Care Med 2019;45:563-72.

\section{Figures}




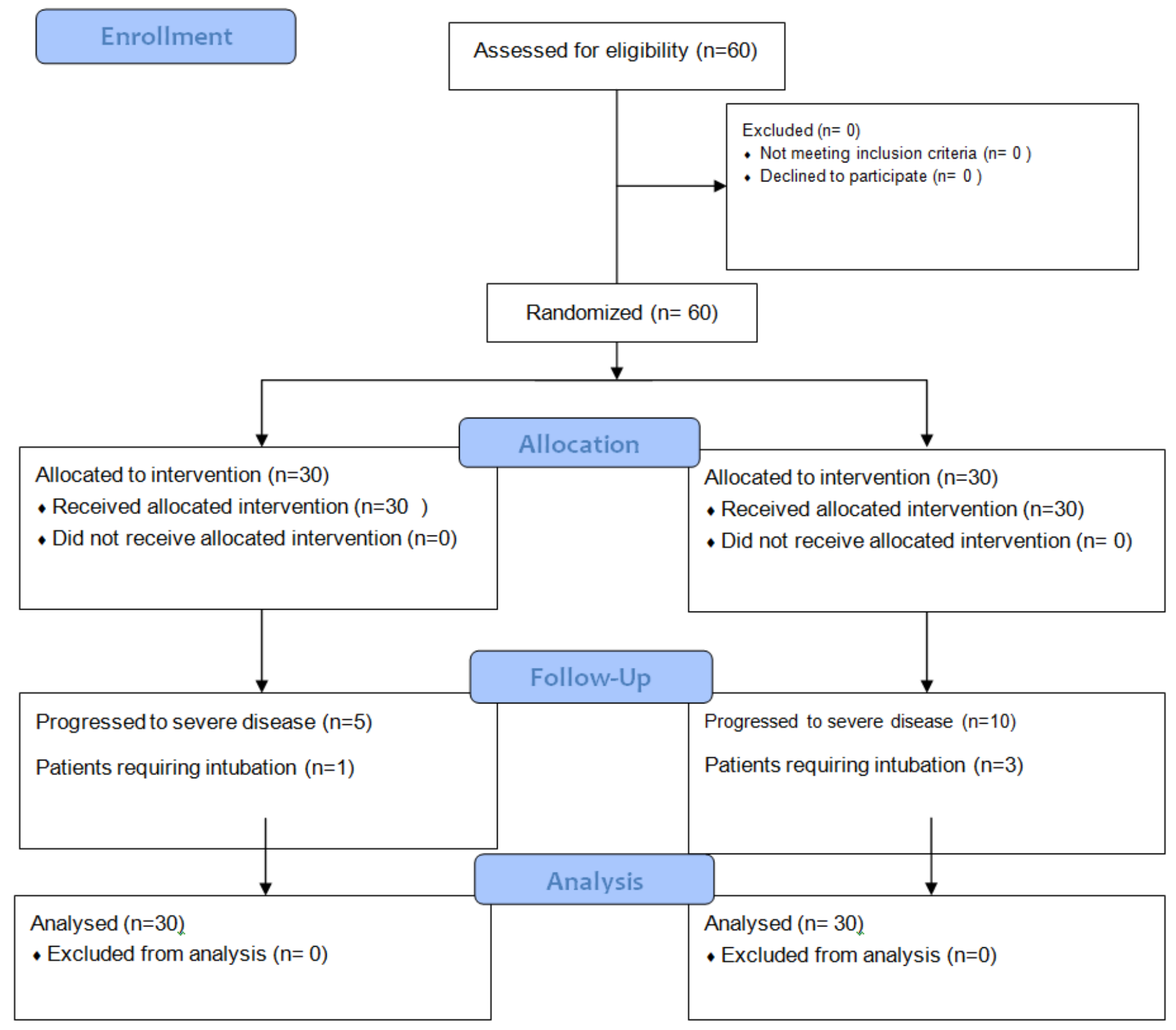

Figure 1

Consort Flow Diagram. 


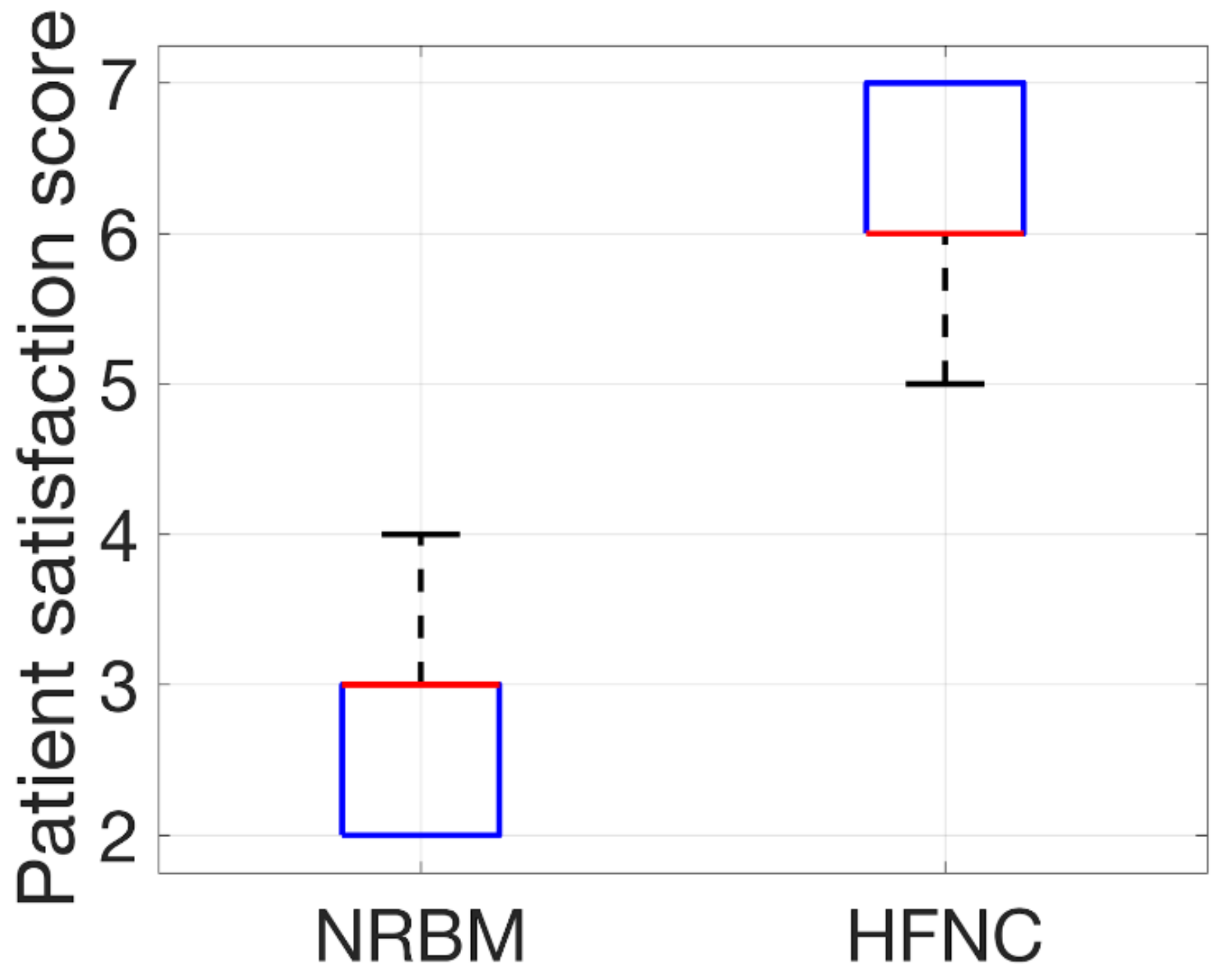

Figure 2

Box Plot Depicting Patient Satisfaction Score on the Study Device. 